\title{
Drawability of Hybrid Type Lightweight Copper Clad Cup*1
}

\author{
Yasunori Harada $^{1, * 2}$, Hiroto Ono ${ }^{1, * 3}$, Yuki Nishikubo ${ }^{2, * 4}$ and Narishige Maeda ${ }^{2, * 4}$ \\ ${ }^{1}$ Graduate School of Engineering, University of Hyogo, Himeji 671-2280, Japan \\ ${ }^{2}$ School of Engineering, University of Hyogo, Himeji 671-2280, Japan
}

\begin{abstract}
In order to increase the number of applications of a copper cup, the formability of copper-resin-copper laminated sheets by the deep drawing process was investigated. Pure copper is a ductile metal with very high electrical conductivity, and its density is higher than that of aluminum and titanium. As part of the copper cup is made of resin, a reduction in the weight of the cup can be achieved. Furthermore, heat is more likely to be retained in the clad cup, and the resin clad structure provides protection for the contents from vibrations, like a vibrationdamping composite steel plate. In the experiment conducted in this work, the materials employed were pure copper and resins, which were polycarbonate plastic (PC), nylon $66(66 \mathrm{~N})$, polyvinyl chloride (PVC), and polyethylene terephthalate (PET). PC is commonly used due to its impact resistance. The initial thickness of the sheets varied from 0.2 to $0.5 \mathrm{~mm}$ and their blank diameter was $70 \mathrm{~mm}$. The punch and the die, whose shoulder radius were $3 \mathrm{~mm}$ and $4 \mathrm{~mm}$ respectively, were made from cold tool steel JIS-SKD11 and the clearance between them was the same as the thickness of the laminated sheet. The deep drawing process was performed using an oil hydraulic press at a forming speed of approximately $10 \mathrm{~mm} / \mathrm{min}$. The laminated sheet was constituted by interposing the resin sheet between two stacked copper sheets. The laminated sheet was employed in the deep drawing process and a flat blank was formed into a circle by the punch. The multistage deep drawing process was, thereafter, employed to investigate the formability of the laminated sheet, which was successfully drawn without cracks. No failure conditions were identified at the bottom or side wall of the drawn cup. Many wrinkles, however, were observed on the opening of the cup, as no pressure was applied in this region by the blank holder during the deep drawing. The section of the drawn cup was observed to examine the formability of the resin sheet, which was within the desirable values. At the bottom corner of the clad cup, the reduction rate of the total thickness was lower than 6\%. [doi:10.2320/matertrans.MT-M2019195]
\end{abstract}

(Received July 19, 2019; Accepted September 6, 2019; Published November 25, 2019)

Keywords: copper, sheet forming, deep drawing, formability, drawn cup, laminated sheet, resin, polycarbonate plastic, cladding

\section{Introduction}

In recent years, resource and energy savings are becoming more important in the industrial field, as well as the functionalization and weight reduction of the product. In particular, commercialization has been carried out using composite technology, such as the cladding materials are attracting attention as the composite material. Composite materials, which are formed by combining materials with different features, ${ }^{1)}$ have the same characteristics as those of the inputted ones. Copper is a metallic material commonly used in the industry, as it has high corrosion resistance, thermal conductivity, electrical characteristics, and workability. ${ }^{2)}$ Many studies have been conducted regarding copper as well as copper alloys on the development of functional clad materials. ${ }^{3,4)}$ For clad materials manufactured by techniques such as rolling and explosive bonding, however, a brittle intermetallic compound may be generated at the bonded interface, ${ }^{5,6)}$ making press forming processes, such as the deep drawing process, of these compounds difficult. Furthermore, in the case of copper and its alloys, the metals to be combined are often limited. ${ }^{7)}$ In addition, as the specific gravity of copper is larger than that of aluminum and titanium alloys, weight reduction is difficult to be attained. We focused on deep drawing of the clad sheet composed of copper and resin. Resins have low heat resistance and strength compared to metals. The resulting cup, however, can be applied in the medical and the food sector, as it is lightweight.

\footnotetext{
${ }^{* 1}$ This Paper was Originally Published in Japanese in J. Japan Inst. Copper 57 (2018) 142-147.

${ }^{* 2}$ Corresponding author, E-mail: harada@eng.u-hyogo.ac.jp

${ }^{* 3}$ Graduate Student, University of Hyogo

${ }^{* 4}$ Undergraduate Student, University of Hyogo
}

In the present study, to reduce the weight of the copper cup, and experiment was conducted to form a copper clad cup combined with resin. The deep drawing method was performed with the copper and resin sheet stacked to each other. Afterwards, the forming of the clad cup was performed and the formability of the copper laminated sheet combined with resin was examined.

\section{Experimental Procedure}

\subsection{Material}

The blanks ( $70 \mathrm{~mm}$ in diameter) were made of a thin sheet of commercially available pure copper C1100 and heat plasticity resin. Four types of resins, including polycarbonate (PC), 66 nylon $(66 \mathrm{~N})$, polyvinyl chloride (PVC), and polyethylene terephthalate (PET), three types of copper sheets, whose thickness were $0.2 \mathrm{~mm}, 0.3 \mathrm{~mm}$, and $0.5 \mathrm{~mm}$, and two types of the resin sheets, $0.4 \mathrm{~mm}$ and $0.5 \mathrm{~mm}$ in thickness were tested. Furthermore, the total thickness of the laminated sheet was $1.0 \mathrm{~mm}$. After combining copper and the resin sheets of different thickness, the clad cup was formed by using two-layer and three-layer laminates. Table 1 shows seven combinations of laminated sheets, named type A to type $\mathrm{G}$.

\subsection{Deep drawing}

After the copper and resin blanks were placed on the die, the deep drawing process was performed by applying a wrinkle holding force of approximately $6 \mathrm{kN}$. Figure 1 shows the outline of the deep drawing device. Furthermore, the multistage treatment was also performed to produce a longer cup, by employing a taper die for the deep drawing in the second and subsequent stages. The blank holding force was 
Table 1 Laminated sheets.

\begin{tabular}{|c|c|c|c|}
\hline $\mathrm{T}$ y $\mathrm{p}$ e & In s i d e & $\mathrm{Center}$ & $\mathrm{Outside}$ \\
\hline A & $\mathrm{P} \mathrm{C}, \quad 0.5 \mathrm{~m} \mathrm{~m}$ & - & $\mathrm{Cu}, \quad 0.5 \mathrm{~m} \mathrm{~m}$ \\
\hline $\mathrm{B}$ & \multirow{2}{*}{$\mathrm{Cu}, \quad 0.3 \mathrm{~m} \mathrm{~m}$} & $\mathrm{P} \mathrm{C}, \quad 0.5 \mathrm{~m} \mathrm{~m}$ & $\mathrm{Cu}, \quad 0.2 \mathrm{~m} \mathrm{~m}$ \\
\hline $\mathrm{C}$ & & $\mathrm{P} \mathrm{C}, 0.4 \mathrm{~m} \mathrm{~m}$ & $\mathrm{Cu}, \quad 0.3 \mathrm{~m} \mathrm{~m}$ \\
\hline $\mathrm{D}$ & \multirow{4}{*}{$\mathrm{Cu}, \quad 0.2 \mathrm{~m} \mathrm{~m}$} & $\mathrm{P} \mathrm{C}, \quad 0.5 \mathrm{~m} \mathrm{~m}$ & \multirow{4}{*}{$\mathrm{Cu}, \quad 0.3 \mathrm{~m} \mathrm{~m}$} \\
\hline $\mathrm{E}$ & & $\mathrm{PVC}, 0.5 \mathrm{~m} \mathrm{~m}$ & \\
\hline $\mathrm{F}$ & & $66 \mathrm{~N}, 0.5 \mathrm{~m} \mathrm{~m}$ & \\
\hline G & & $\mathrm{PE} \mathrm{T}, 0.5 \mathrm{~m} \mathrm{~m}$ & \\
\hline
\end{tabular}

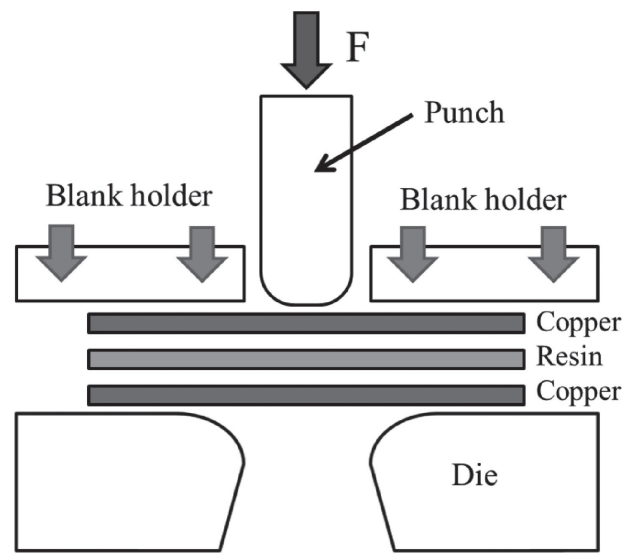

Fig. 1 Clad cup by deep drawing.

performed without any load and the angle of the taper die was 60 degrees. The clearance between the punch and the die was the same as the total thickness of the laminate at all drawing stages. The lubricant used was the molybdenum disulfide lubricating oil. Table 2 shows the processing conditions.

\subsection{Thickness strain}

The thickness distribution of the resulting cup was investigated by measuring the thickness of each sheet, after cutting the cup in half. As the copper sheet was processed by rolling, due to the anisotropy of the blank, the sheet thickness was measured in three directions: at 0,45 and 90 degrees with respect to the rolling direction. In the case of resins, except PC, the springback after the formation of the cup was large, making it difficult to measure the thickness of the resin. As the result, only the thickness of the inner and outer copper sheets of the clad cup were measured.

\subsection{Tensile test}

A tensile test was conducted to investigate the mechanical properties of the pure copper sheet. The workpiece, whose width and length were $6.5 \mathrm{~mm}$ and $25 \mathrm{~mm}$, was half the size of the JIS 13 B. The tensile test speed was $2 \mathrm{~mm} / \mathrm{min}$. Furthermore, the anisotropy was also examined, as the thin sheet was composed of a rolled material. The samples were taken from three directions, which were the same as those that the thickness were measured.

\section{Results and Discussions}

\subsection{Tensile properties of each sheet}

A tensile test was conducted to investigate the tensile properties of the copper and resin sheets. In the copper case, tensile test workpieces, collected from three directions $(0,45$ and 90 degrees based on rolling direction) were evaluated. Table 3 shows the fracture elongation and the maximum tensile strength obtained for both sheets. In the case of the

Table 2 Deep drawing condition of laminated sheets.

\begin{tabular}{|c|c|c|c|}
\hline \multicolumn{2}{|c|}{$\mathrm{St}$ a g e $\mathrm{number}$} & $1 \mathrm{~s} \mathrm{t}$ & $2-5 \mathrm{th}$ \\
\hline \multicolumn{2}{|c|}{ B la n k holder force / k N } & 6 & 0 \\
\hline \multirow{3}{*}{$\mathrm{D}$ i e $\mathrm{s}$} & M a t e ri a 1 & \multicolumn{2}{|c|}{ S K D 11} \\
\hline & $\mathrm{D}$ i a $\mathrm{met}$ e $\mathrm{r} / \mathrm{m} \mathrm{m}$ & 42 & $36-20$ \\
\hline & Corner radius $/ \mathrm{mm}$ & 4.0 & 2.0 \\
\hline \multirow{3}{*}{$\mathrm{Punch}$ e s } & M a t e r i a 1 & \multicolumn{2}{|c|}{ S K D $11, \quad$ S U J 2} \\
\hline & $\mathrm{D}$ i a $\mathrm{met}$ e $\mathrm{r} / \mathrm{m} \mathrm{m}$ & 40 & $34-18$ \\
\hline & Corner radius / m m & 3.0 & 3.0 \\
\hline \multicolumn{2}{|c|}{$\mathrm{C} 1 \mathrm{e}$ arance $/ \mathrm{mm}$} & \multicolumn{2}{|c|}{1.0} \\
\hline
\end{tabular}


Table 3 Tensile property of copper sheet and resin sheet.

\begin{tabular}{|c|c|c|c|}
\hline $\mathrm{S} \mathrm{h}$ e e $\mathrm{t}$ & $\begin{array}{l}\text { Collection } \\
\text { a ngle } \\
(\mathrm{degree})\end{array}$ & $\begin{array}{l}\text { Fracture } \\
\text { e } 1 \text { o n gation } \\
(\%)\end{array}$ & 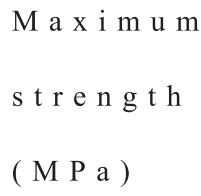 \\
\hline \multirow{3}{*}{$\begin{array}{l}\text { Cop p e r } \\
0.5 \mathrm{~m} \mathrm{~m}\end{array}$} & 0 & 37.1 & 216.7 \\
\hline & 45 & 61.1 & 218.7 \\
\hline & 90 & 39.1 & 203.8 \\
\hline \multirow{3}{*}{$\begin{array}{l}\text { Cop p e r } \\
0.2 \mathrm{~m} \mathrm{~m}\end{array}$} & 0 & 19.2 & 180.8 \\
\hline & 45 & 20.9 & 182.7 \\
\hline & 90 & 15.7 & 181.0 \\
\hline \multirow{3}{*}{$\begin{array}{l}\text { Cop p e r } \\
0.3 \mathrm{~m} \mathrm{~m}\end{array}$} & 0 & 26.9 & 177.9 \\
\hline & 45 & 30.9 & 180.1 \\
\hline & 90 & 21.8 & 179.1 \\
\hline $\mathrm{PC} \quad 0.5 \mathrm{~m} \mathrm{~m}$ & - & 111 & 60.2 \\
\hline $\mathrm{PVC} \quad 0.5 \mathrm{~m} \mathrm{~m}$ & - & 575 & 16.7 \\
\hline $66 \mathrm{~N} \quad 0.5 \mathrm{~m} \mathrm{~m}$ & - & 413 & 68.3 \\
\hline $\mathrm{PET} \quad 0.5 \mathrm{~m} \mathrm{~m}$ & - & 520 & 14.8 \\
\hline
\end{tabular}

copper sheet, the fracture elongation was higher than approximately $37 \%$ for the workpiece with $0.5 \mathrm{~mm}$ in thickness and varied from $16 \%$ to $31 \%$ for those with $0.2 \mathrm{~mm}$ and $0.3 \mathrm{~mm}$ in thickness. Anisotropy was also observed, and the sample in the 90 degrees direction showed the lowest value. Furthermore, the maximum tensile strength did not differ much in the copper sheets. For thin sheets (thickness of $0.2 \mathrm{~mm}$ and $0.3 \mathrm{~mm}$ ), the maximum values were approximately $182 \mathrm{MPa}$ and approximately $179 \mathrm{MPa}$. In the case of the resin sheets, the fracture elongation was much larger than that of the copper one. The elongation of the PC resin, which was the lowest among resin sheets, was approximately $110 \%$. The maximum tensile strength of the $\mathrm{PC}$ and $66 \mathrm{~N}$ resin varied from $50 \mathrm{MPa}$ to $70 \mathrm{MPa}$, while the PVC and PET resin ranged from $15 \mathrm{MPa}$ to $17 \mathrm{MPa}$. The maximum strengths of $\mathrm{PC}$ and $66 \mathrm{~N}$ were several times higher than those of PVC and PET. Figure 2 shows the relationship between nominal stress and nominal strain.

\subsection{Formability of the laminated $\mathrm{PC}$ resin sheet}

The two-layer laminated sheet combined with the $\mathrm{PC}$ resin was used, and its forming was performed by the multistage deep drawing process. Figure 3 shows the appearance of clad cup generated from the two-layer laminated sheet (type A) combining with the PC sheet and copper sheet. Both of them have a thickness of $0.5 \mathrm{~mm}$. In the multistage deep drawing

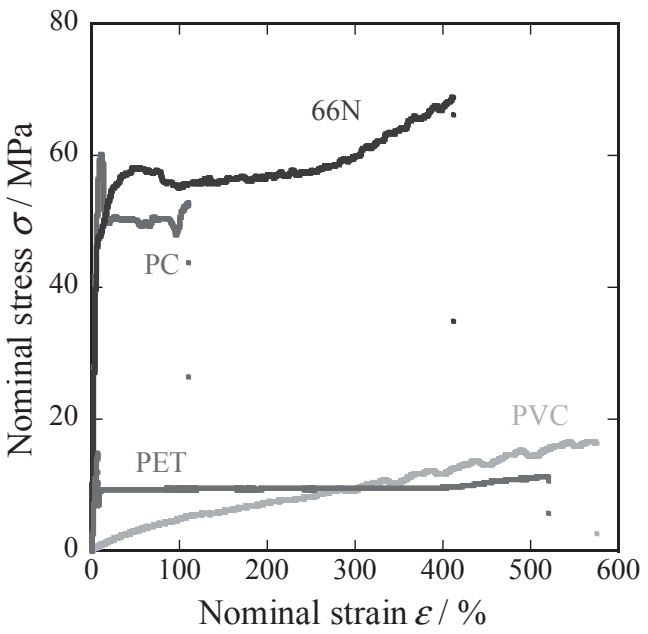

Fig. 2 Nominal stress-nominal strain curve.
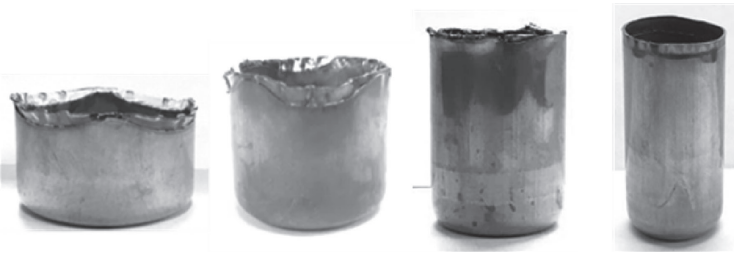

Fig. 3 Appearance of drawn cups (type A). 


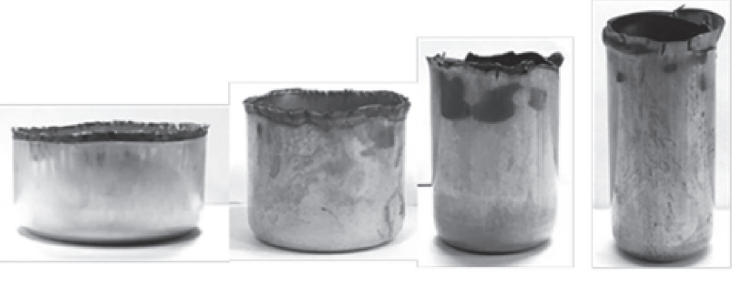

Type B
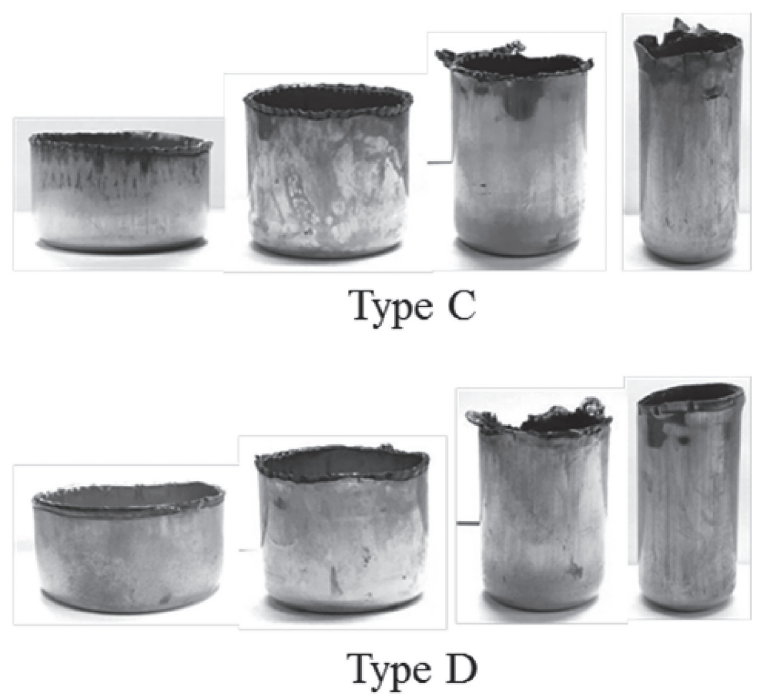

Fig. 4 Appearances of drawn cups (type B, C, D).

process, from the first to fourth stages, the formability of the drawn cup was sufficient and no fracture at the bottom or wall occurred. Although the resin and copper, which were strongly attached to each other, of the clad cup are not bonded to each other, the cup could be separated by handling, due to the large springback of the resin. In addition, wrinkles were observed at the opening of the drawn cup, as the blank holding force was not sufficient at the opening. As a result, the ductility of the resin was considerably larger than that of copper. It is considered that the restraining force of the punch is reduced at the shoulder of the die. Furthermore, in the case of the copper sheet of $0.5 \mathrm{~mm}$, the anisotropy was large. As a region from the lamination to the single layer at the opening exists, the blank holding force became uneven. In the third cup and subsequent cups, fracture occurred near the opening due to the presence of wrinkles. At those stages, therefore, the vicinity of the opening was removed by cutting, and the forming at the fourth stage was performed afterwards. The multistage deep drawing process was performed on the threelayer laminated sheet combined with PC. Figure 4 shows the appearance of the clad cup obtained from the three-layer laminated sheets (types B, C, D) combining the PC and copper sheet. Wrinkles were observed at the opening of all cups, however, forming was possible up to the fourth stage for any combination. At the third stage, in particular, the wrinkled edge was cut and removed, and the forming was performed at the fourth stage. In the case of laminated sheet combined with PC, the drawn cup exhibited formability values within the desirable ranges. As the drawability of resin itself was not known, however, the drawability of resin was examined. Figure 5 shows the appearance of the PC cup of

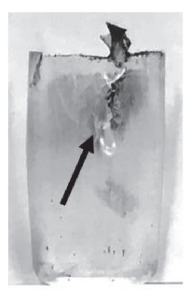

Type A

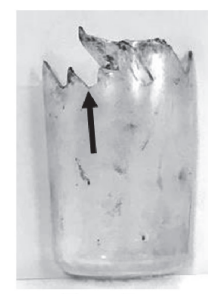

Type B

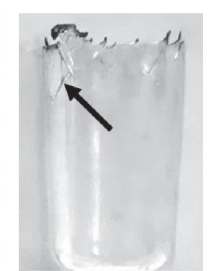

Type C

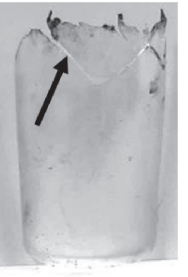

Type D
Fig. 5 Appearance of resin cup (PC).

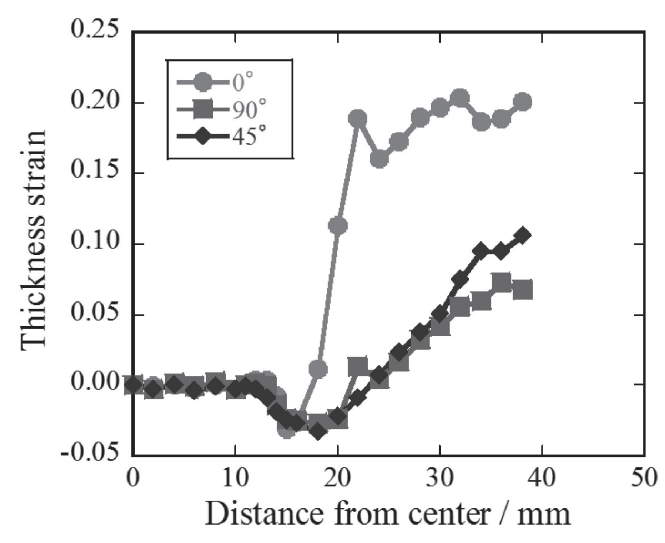

Fig. 6 Distribution of thickness strain (type C).

the fourth drawn cup composed of two (type A) and three layers (type B, C, D). The resin cup was cut in half in the longitudinal direction. In the case of the resin cups, the occurrence of cracking at the bottom of the cup was not observed, however, the occurrence of large cracks (arrows in the figure) was observed at the opening. It is, therefore, assumed that the resin was broken by the wrinkles generated at the opening of the second to third stage cups.

For the laminated sheet with PC, the thickness of the drawn cup was also measured. Figure 6 shows the thickness strain distribution of the cup type $\mathrm{C}$ at the first stage. The measurement was performed in the three directions to take the anisotropy of the sample into consideration. The thickness (including the PC resin) was measured toward the opening from the bottom center of the cup. In the 0 degree direction, the increase in thickness strain was larger than those in the other directions. Furthermore, the greatest reduction in thickness strain (approximately -4\%) occurred at the bottom corner of the cup. Similarly, for types A, B and D cups, the thickness strain was similar to the type C cup. The thickness strain in the 0 degree direction increased. In addition, the decrease in thickness ranged from $4 \%$ to $6 \%$ at the bottom of the cup. In order to investigate the thickness change of the drawn cup formed by the multistage deep drawing process, the thickness at the second and third stages was measured (only for the 0 degree direction). Figure 7 shows the thickness strain distribution of the type $C$ cup in the first, second, and third stages. The increase in the thickness strain was noticeable at the side walls of the drawn cup at the first and second stages, however, at the third stage, the increase of the thickness strain was almost imperceptibly. It is assumed, therefore, that the material flow in the side wall increases as the diameter of decreases, as the tensile and compressive deformations, occurring in the deep drawing and 


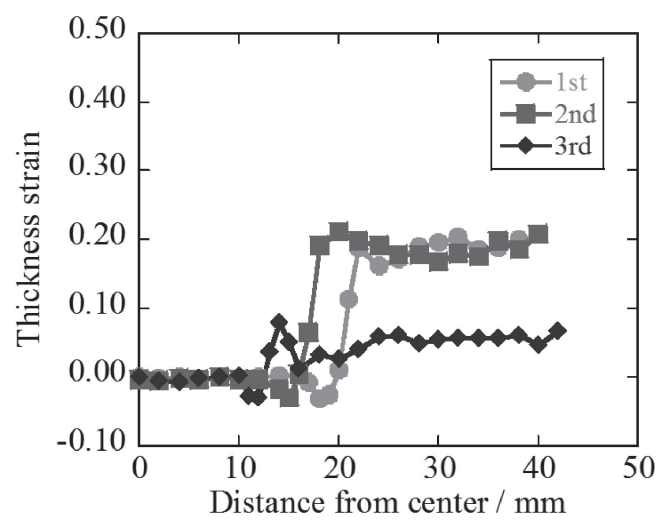

Fig. 7 Distribution of thickness strain (type C).

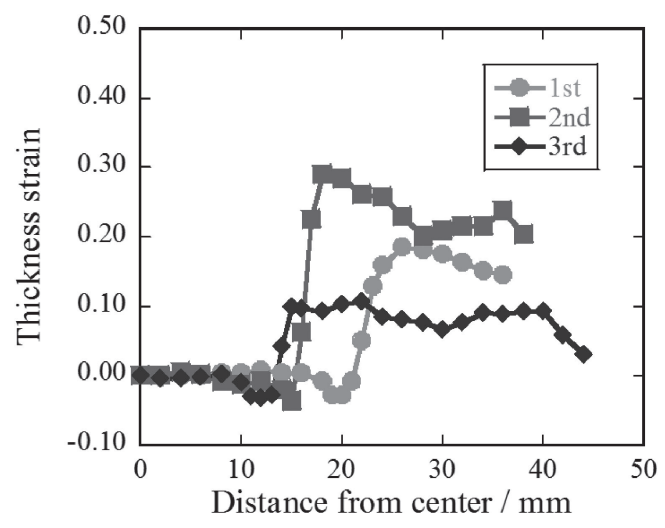

Fig. 8 Distribution of thickness strain (type D).

circumferential directions, respectively, increase. In addition, thickness strain distribution of the types A, B and D drawn cups in the multistage deep drawing showed a tendency similar to that of the type $\mathrm{C}$ drawn cup. Figure 8 shows the thickness strain distribution of the type D drawn cup.

\subsection{Formability of the laminated sheet (except the PC sheet)}

For the three-layer laminated sheets (type E, F, G) combined with the resins, except PC, the formability was investigated by the multistage deep drawing process. Figure 9 shows the appearance of the clad cup formed by the multistage deep drawing process for the types E, F, G sheets, in which the resin (except PC) and pure copper sheets were combined. For the PC cup case, when wrinkles occurred at the edge of the cup at the third stage and the area was removed. Although wrinkles were observed at the opening, all cups were able to be fabricated using the multistage deep drawing. In the case of type F, the drawn cup at the fifth stage was be formed as the edge of the drawn cup at the third stage was removed. For the type $\mathrm{E}$ and $\mathrm{G}$ cases, however, the forming of the cup at the fifth stage suffered from severe wrinkling at the cup edge, therefore, good formability could not be attained. Moreover, at the first, second, and third stages, the protruded resin was noticed at the cup edge. From the results of tensile properties of resin (Fig. 2), it was considered that the elongation before break of the resins, other than PC, was large. For the cups formed from the threelayer laminated sheet combined with each resin, wrinkles

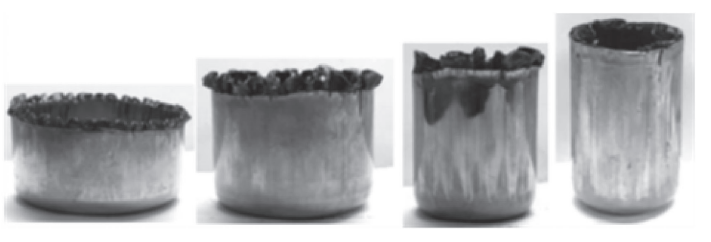

Type E

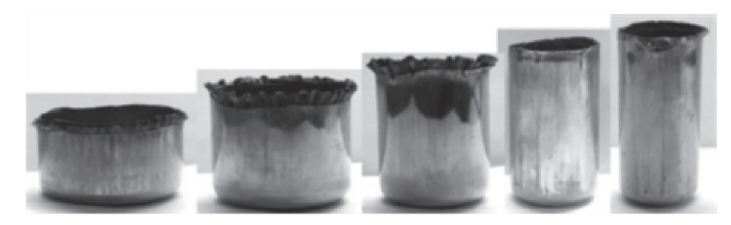

Type F

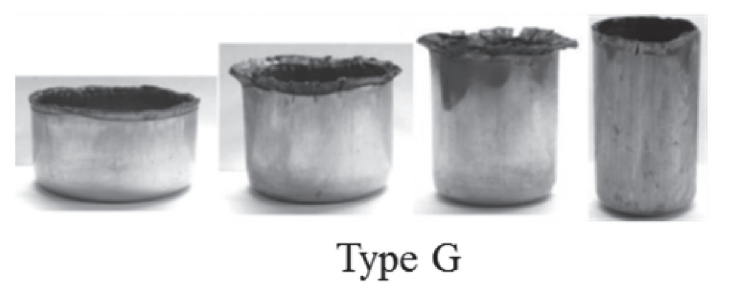

Fig. 9 Appearances of drawn cups (type E, F, G).

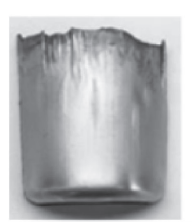

$\mathrm{PC}$

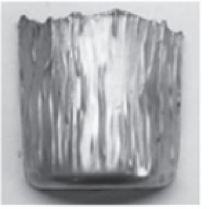

PVC

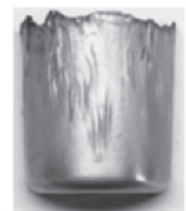

$66 \mathrm{~N}$

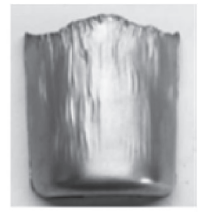

PET
Fig. 10 Inside copper cup at third stage.

were observed inside the cup at the second stage. Furthermore, wrinkles were prominent on the inner surface of the cup as the stage number increased. As the thickness of the copper sheet placed inside the cup was $0.2 \mathrm{~mm}$, it was assumed that the buckling occurred due to the compressive force in the cup circumferential direction. Figure 10 shows the inner surface of the inner copper cup at the third stage (types D, E, F, and G). The copper cup was removed by cutting the clad cup in half. The number of wrinkles was the highest for copper cups combined with PVC, as PVC has high fracture elongation and low strength (Fig. 2), making the inner copper cup be easily deformed. The thickness of the cups was also measured to investigate the effect of the different resins. For all resins, except PC, however, the thickness distortion of the copper cup was the only one that could be measured. No significant decrease in copper thickness at the bottom corner of the cup was noticed. Figure 11 shows the thickness strain in the 0 degree from the rolling direction in the type $\mathrm{F}$ drawn cup, in the first through third stages. An increase in thickness strain was observed on the side wall at the first stage. In addition, the thickness strain did not significantly decrease at the side wall for the third stage. It is assumed that the material flow was slow due to the wrinkles generated in the side wall. The change in thickness 


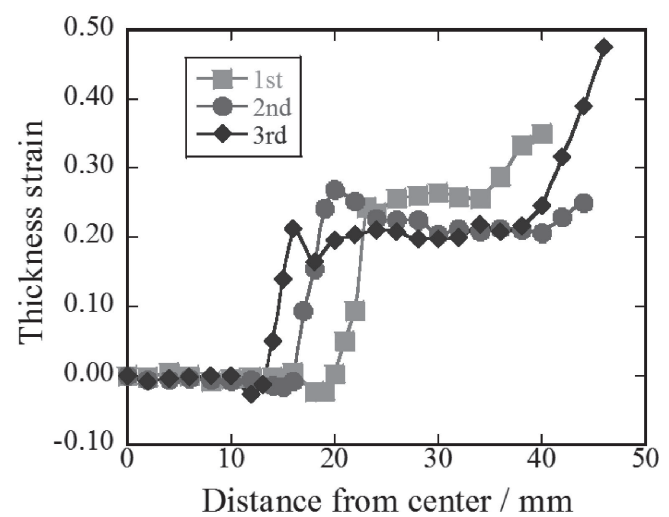

Fig. 11 Distribution of thickness strain (type F).

strain, however, was small at the bottom of the cup. For types $\mathrm{E}$ and $\mathrm{G}$ cups at the first through third stages, the thickness strain in the 0 degree direction was also similarly distributed.

\section{Conclusions}

The formability of pure copper clad sheet by the multistage deep drawing process was investigated to enhance reduce the weight of the copper cup. The conclusions obtained are as follows.

(1) In the multistage deep drawing process, the clad cup combined with the PC resin showed good formability up to the third stages. In the fourth stage, however, several cracks occurred at the opening of the drawn cup.

(2) For the copper-PVC and copper-PET combinations, the resulting cup could be formed up to the fourth stage. In the case of copper- $66 \mathrm{~N}$, the drawn cup could be formed up to the fifth stage.
(3) For the copper-PC case, the difference in thickness strain from the first stage to the third stage was small. The reduction of thickness strain was less than approximately 0.06 .

(4) In the combination of the resin $66 \mathrm{~N}, \mathrm{PVC}$, and PET, the reduction of thickness strain was small at the corner of the cup from the first stage to the third stage.

(5) The production of copper clad cups using several types of resins was possible, as well as the weight reduction of the copper cup. As a result, applications in the medical and food, as a cup for sterilization, are possible.

\section{Acknowledgments}

The authors would like to thank Mr. S. Hattori, a former engineering undergraduate at University of Hyogo, for his help in the experimental work. This research was supported in part by a grant from the Japan Institute of Copper.

\section{REFERENCES}

1) A. Yamamoto, T. Nagatani and Y. Takahashi: Titanium 47 (1999) 218226.

2) A. Kakitani, T. Niimi, Y. Kawasaki, M. Nagano and T. Hatano: J. Japan Inst. Copper 56 (2017) 276-281.

3) H. Hachino, F. Horii, T. Otaka and K. Konishi: The Hitachi Densen (3) (1983) 57-60.

4) K. Okamoto and M. Kuroda: Technical Report of Totan, No. 2, (Tokyo Tungsten Co., Ltd., 1990) pp. 12-14.

5) T. Kawanami, A. Segawa, Y. Kanai and H. Tagami: J. Japan Inst. Copper 41 (2002) 288-292.

6) W. Xie, T. Yamaguchi and K. Nishio: J. Japan Inst. Met. Mater. 75 (2011) 166-172.

7) S. Katayama: Rev. Laser Eng. 38 (2010) 594-602. 